\title{
ANALYSIS OF MECHANICAL STRENGTH TO FIXING THE FEMORAL NECK FRACTURE IN SYNTHETIC BONE TYPE ASNIS
}

\author{
Anderson Freitas ${ }^{1}$, Welder Fernandes lula ${ }^{1}$, Jonathan Sampaio de Oliveira ${ }^{1}$, Rafael Almeida Maciel ${ }^{1}$, \\ Diogo Ranier de Macedo Souto ${ }^{1}$, Patrick Fernandes Godinho ${ }^{1}$
}

\section{ABSTRACT}

Objective: To analyze the results of biomechanical assays of fixation of Pauwels type III femoral neck fracture in synthetic bone, using $7.5 \mathrm{~mm}$ cannulated screws in inverted triangle formation, in relation to the control group. Methods: Ten synthetic bones were used, from a domestic brand, divided into two groups: test and control. In the test group, a $70^{\circ}$ tilt osteotomy of the femoral neck was fixated using three cannulated screws in inverted triangle formation. The resistance of this fixation and its rotational deviation were analyzed at $5 \mathrm{~mm}$ displacement (phase 1) and 10mm displacement (phase 2). The control group was tested in its integrity until the fracture of the femoral neck occurred. The Mann-Whitney test was used for group analysis and comparison. Results: The values in the test group in phase 1, in samples 1-5, showed a mean of $579 \mathrm{~N}$ and $\mathrm{SD}=77 \mathrm{~N}$. Rotational deviations showed a mean of $3.33^{\circ}, \mathrm{SD}=2.63^{\circ}$. In phase 2 , the mean was $696 \mathrm{~N}$ and $\mathrm{SD}$ $=106 \mathrm{~N}$. The values of the maximum load in the control group had a mean of $1329 \mathrm{~N}$ and $\mathrm{SD}=177 \mathrm{~N}$. Conclusion: The analysis of mechanical strength between the groups determined a statistically significant lower value in the test group. Level of Evidence III, Control Case.

Keywords: Femoral neck fractures. Fracture fixation, internal. Biomechanical phenomena.

Citation: Freitas A, Lula WF, Oliveira JS, Maciel RA, Souto DRM, Godinho PF. Analysis of mechanical strength to fixing the femoral neck fracture in synthetic bone type ASNIS. Acta Ortop Bras. [online]. 2014;22(4):206-9. Available from URL: http://www.scielo.br/aob.

\section{INTRODUCTION}

Femoral neck fractures are becoming a common traumatology entity, especially in elderly patients which demand high cost for its treatment. ${ }^{1}$ According to the World Health Organization (WHO) it is estimated that in 20506.3 million of the fractures of the proximal end of the will occur, three times higher than today, and half of them being in Ásia. ${ }^{2}$

Treatment of femoral neck fracture is defined based on the fracture pattern, bone quality, comorbidities and the physiological age of the patient. However, there is no doubt about the benefit of surgical treatment, which reduces the rate of morbidity and mortality. Such treatments are defined as joint replacement or fracture fixation. ${ }^{3}$ Asnis in 1994 described the method of fixation of femoral neck fracture with cannulated screws in the inverted triangle configuration, one in the lower portion of the neck and two other screws in the anterior and posterior portions, respectively in this order of fixation. ${ }^{4}$

The various methods described for fixation of the fracture type
(Pauwels III), namely dynamic hip screw (DHS), Asnis mounting cannulated screws, and non-parallel cannulated screws show significant rates of complications. Due to mechanical instability of the fracture or to intrinsic or extrinsic factors of the fracture and/or the patient. ${ }^{5}$ The authors propose a statistical analysis of the values obtained in mechanical tests on pre-osteotomized synthetic bones, simulating a Pauwels type III fracture and fixed with $7.5 \mathrm{~mm}$ cannulated screw using the inverted triangle mounting (Asnis) and the control group.

\section{MATERIALS AND METHODS}

Ten synthetic bone of the third proximal femur from a national brand of the same batch were used, divided into two groups, the test group and control group.

In the test group, formed by five of this synthetic models with 200 $\mathrm{mm}$ length, still intact, three guide wires were introduced using a parallel tutor with the aid of fluoroscopy, in the shape of an inverted triangle, with a lower tangent the lower part of the femoral

All the authors declare that there is no potential conflict of interest referring to this article.

1. Hospital Ortopédico e Medicina Especializada (HOME), Brasília, DF, Brazil.

Work developed at Serviço de Quadril do Hospital Ortopédico e Medicina Especializada (HOME), Brasília, DF, Brazil, and Fundação de Ensino e Pesquisa em Ciência da Saúde (FEPECS), Brasília, DF, Brazil.

Correspondência: HOME - Hospital Ortopédico e Medicina Especializada- SGAS Quadra 613, Conjunto C 70200-730 Brasilia, DF, Brasil. andfreitas28@gmail.com 
neck and two others above this, being one in the anterior portion of the femoral neck and the other in the posterior part, touching the cortex corresponding to this region, all parallel to each other. After confirmation of proper placement, there were drilled with specific drills up to $5 \mathrm{~mm}$ before reaching the articular surface of the femoral head. Having performed this step with synthetic bones intact allows anatomical reduction and optimization of compression of the fracture focus after osteotomy and fixation. Guides wires are then removed before proceeding to osteotomy at the femoral neck level at $70^{\circ}$ tilt, with the preconfigured template, so that there were no angular differences between the tested bones. Osteotomy was fixed with three $7.5 \mathrm{~mm}$ cannulated screws in holes previously trephined following the sequence: inferior screw, with the aid of a washer, anterior screw and finally the posterior one, all having been radiographed after fixation for assessment of the reduction and screw positioning (Figure 1A and $\mathrm{B}$ ). The analysis of the mechanical assay of this group was divided into two stages: the fixation strength in $5 \mathrm{~mm}$ displacement (Figure 2A and B Stage 1) and the fixation strength in 10 $\mathrm{mm}$ displacement. (Figure 2C Phase 2) Assessment of rotational deviation occurred at the end of phase 1 , with a mark made in the medial face of the femoral neck. (Figure 3A, B)

The control group, which was formed by five $125 \mathrm{~mm}$ long
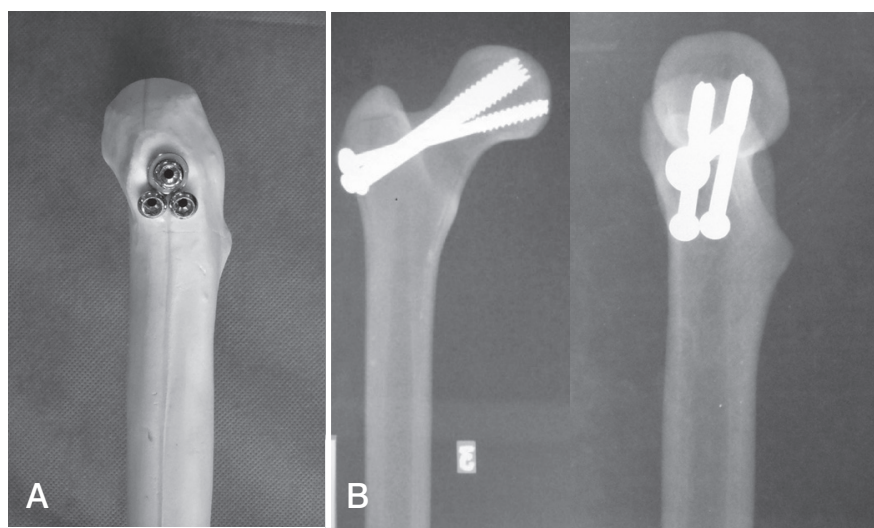

Figure 1. A) Synthetic bone Model fixated with three $7.5 \mathrm{~mm}$ cannulated screws; B) Radiograph of synthetic models fixated for evaluation of proper positioning of the syntheses.
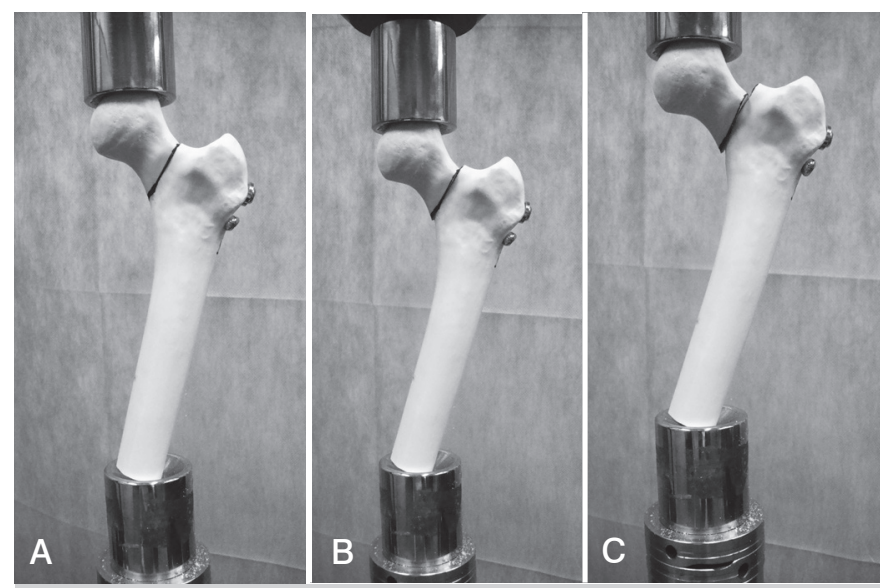

Figure 2. A) Bone model already fixated in the testing machine at pre-test; B) Bone image during the test model at $5 \mathrm{~mm}$ displacement (Step 1); C) Bone model during the test at $10 \mathrm{~mm}$ displacement (Step 2). bones synthetic models, was tested with their integrity intact until the fracture of the femoral neck, (Figure 4A, B) defining, thus, the resistance maximum load prior to fracture occurrence and comparison parameter to resistance to the synthetic method used in the test group.

Both groups were tested on the MTS test machine (MaterialsTesting System) model 810 - FlexTest 40, with $100 \mathrm{kN}$ capacity at a rate of load application of $200 \mathrm{~mm} / \mathrm{min}$. In the test a calibrated and tested cell load with 10kN capacity was used. (Figure 5).

The statistical method used was the Mann-Whitney test for comparison of the maximum force $(\mathrm{N})$ between the control group and test group. A nonparametric method was used since the maximum force is not normally distributed (Gaussian distribution) due to the small sample size analyzed in each group. The criterion for determining statistical significance was set at $5 \%$. Statistical analysis was performed with 6:11 SAS software (SAS Institute, Inc., Cary, North Carolina).
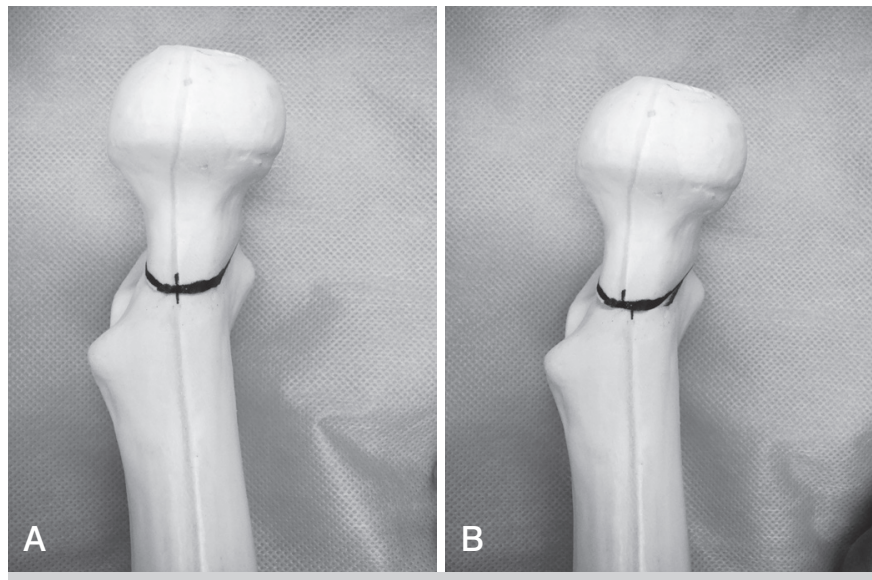

Figure 3. A) Marking for evaluation of pre-test rotational deviation; B) Image of markup misaligned after 1 st Step of essay of the test group.
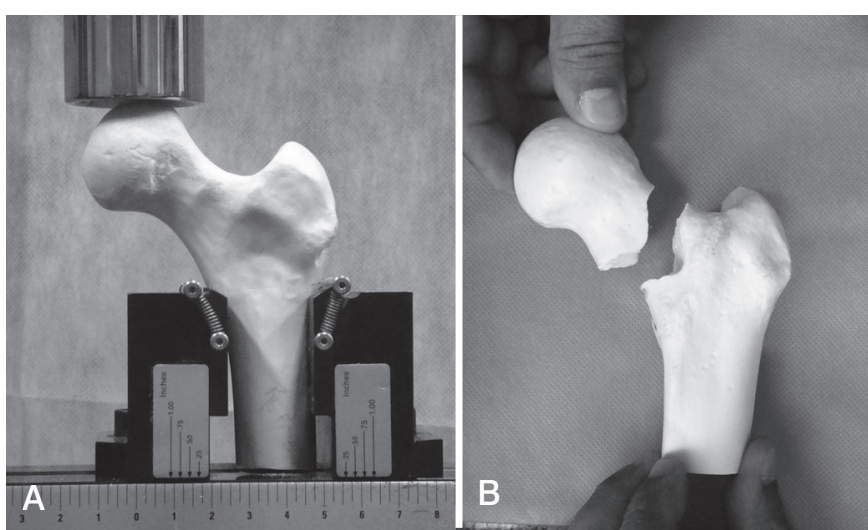

Figure 4. (A) Image of synthetic model of the control group on the test machine at pre-test; (B) Image of synthetic model of the control group at post-test.

\section{RESULTS}

The value of the load in Newtons $(\mathrm{N})$ applied until fracture displacement of $5 \mathrm{~mm}$ (step 1) was 706, 514, 534, 547 and 594, respectively, for samples 1 to 5 , which present as average a value of $579 \mathrm{~N}$ and standard deviation $77 \mathrm{~N}$. The load value until 


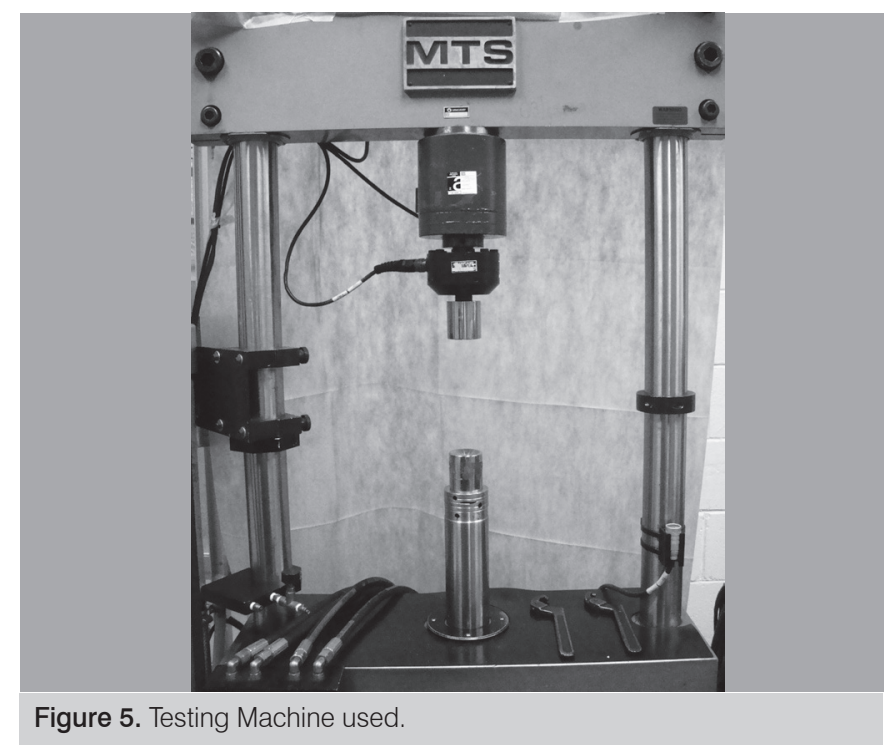

the displacement of fracture by $10 \mathrm{~mm}$ (Phase 2) in Newtons (N) applied to five samples was, respectively, 860,607,614,658 and 743 , which presented as average a value of $696 \mathrm{~N}$ and standard deviation $106 \mathrm{~N}$. The values of the rotational deviation in degrees measured at the end of the phase, respectively, were: $3.27^{\circ}$, $1.64^{\circ}, 5.22^{\circ}, 6.52^{\circ}, 0.0^{\circ}$, which presented as average $3.33^{\circ}$ and standard deviation $2.63^{\circ}$. (Table 1 and Figure 6)

\section{Control group}

The value of maximum load in Newtons (N) applied to the occurrence of femoral neck fracture in the control group respectively in samples 1 to 5: 1544, 1110, 1359, 1194 and 1437, which

Table 1. Values from tests on models of the test group in steps 1 and 2.

\begin{tabular}{c|c|c|c}
\hline Sample & $\begin{array}{c}\text { Load with } \mathbf{5} \mathbf{~ m m} \\
\text { displacement (N) }\end{array}$ & $\begin{array}{c}\text { Load with } \mathbf{1 0} \mathbf{~ m m} \\
\text { displacement (N) }\end{array}$ & $\begin{array}{c}\text { Rotation } \\
\text { (degrees) }\end{array}$ \\
\hline 1 & 706 & 860 & 3.27 \\
\hline 2 & 514 & 607 & 1.64 \\
\hline 3 & 534 & 614 & 5.22 \\
\hline 4 & 547 & 658 & 6.52 \\
\hline 5 & 594 & 743 & 0,0 \\
\hline Mean & 579 & 696 & 3.33 \\
\hline St. Deviation & 77 & 106 & 2.63 \\
\hline
\end{tabular}

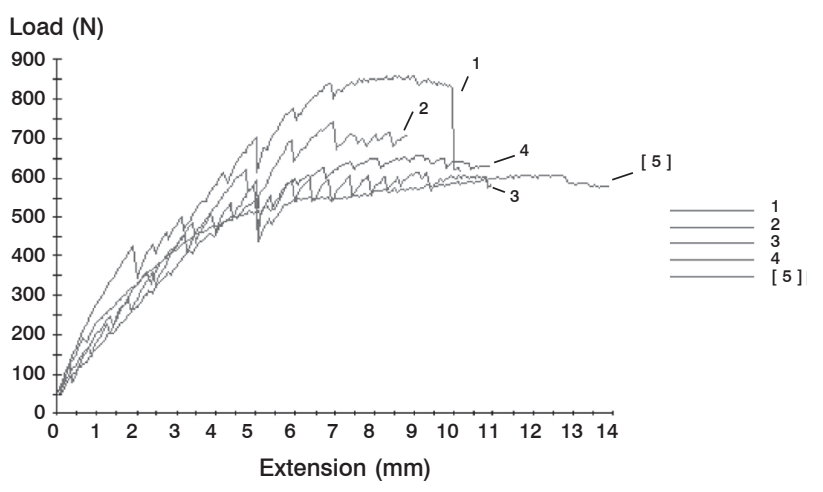

Figure 6. Force versus displacement curve in models testing of the test group. presented as average a value of $1329 \mathrm{~N}$ and standard deviation of $177 \mathrm{~N}$ (Table 2, Figure 7)

According to the Mann-Whitney test, it has been shown that the test group showed maximum force at $10 \mathrm{~mm}$ displacement significantly lower than the control group $(p=0.009)$. (Figure 8$)$

\begin{tabular}{c|c} 
Table 2. Values of assays in samples from the control group. \\
\hline Sample & $\begin{array}{c}\text { Control group } \\
\text { Maximum load (N) }\end{array}$ \\
\hline 1 & 1544 \\
\hline 2 & 1110 \\
\hline 3 & 1359 \\
\hline 4 & 1194 \\
\hline 5 & 1437 \\
\hline Mean & 1329 \\
\hline St. Deviation & 177 \\
\hline
\end{tabular}

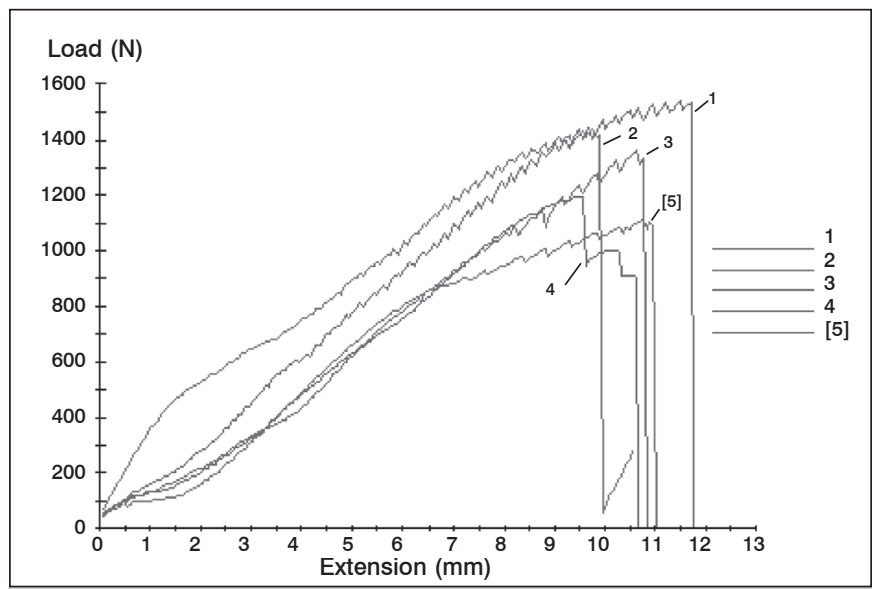

Figure 7. Force versus displacement curves for the control group.

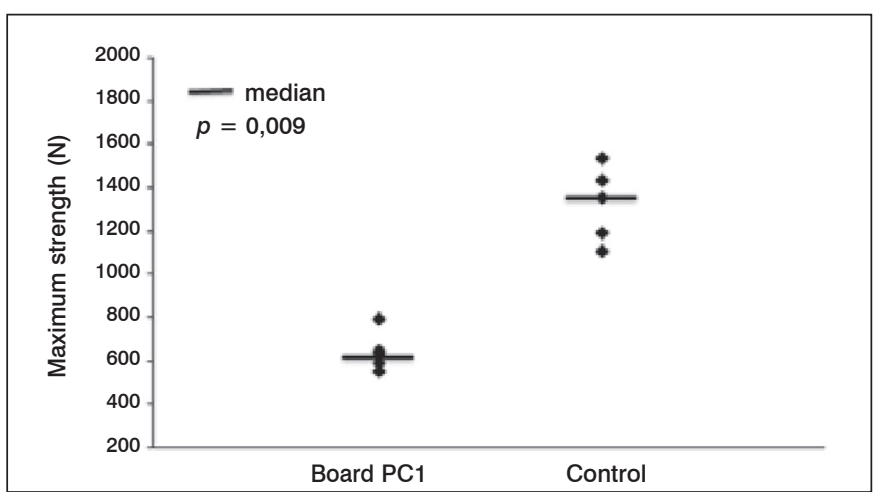

Figure 8. Maximum force at $10 \mathrm{~mm}$ displacement according to test group (PC1 board) and control group.

\section{DISCUSSION}

The main goal in the treatment of femoral neck fracture is to facilitate the patient's return as soon as possible to his usual activities, requiring therefore rigid fracturary stability. ${ }^{6}$

During daily activities, the loads on the femoral head alternate anteriorly and posteriorly, determining varus forces on the femoral head and neck. ${ }^{7}$ According to Zlowodzki et al. ${ }^{8}$ there is no significant increase in fixation force when more than three screws are used for treatment of the femoral neck fracture. Additional factor affecting the stability of the fracture fixation is the involve- 
ment of the posterior wall of the femoral neck, which showed in clinical studies that over half of unstable fractures resulted in pseudoarthrosis. ${ }^{8}$ According to Denham, ${ }^{9}$ the force applied on the femoral head-neck depends on the patient's weight and the activity performed, and this will be critical in the resistance of the implant in femoral neck fractures. We will use as a reference in our study an axial force of $1400 \mathrm{~N}$ as the force applied to the hip of a $70 \mathrm{~kg}$ individual resting on one leg. ${ }^{9}$

The more vertical line of the initial fracture (Pauwels III - especially with an angle $>50^{\circ}$ ) is associated with higher complication rates due to its instability; the majority of studies support the placement of parallel screws. However, some studies have shown that parallelism of the screws is not a foreseeable risk factor for complications, and these also do not mention the ability to stabilize the fracture with this synthesis methodology. ${ }^{10-12}$

Considering unstable Pauwels type III fractures, the use of three cannulated screws shaped as an inverted triangle does not have good outcome, with high implant failure, despite the fact that AO-ASIF group sustain its use, a fact that may be related to poor outcome on mechanical strength measured by this work. ${ }^{12,13}$ We acknowledge the limitations of this study. The use of synthetic instead of cadaver bones do not correctly reflect the anatomy of the femoral trabecular bone and its supporting force. We did not simulate all physiological force components - cyclic, torsional, axial - to which the hip is subjected during ambulation or muscle contraction alone. Directional force vectors could be changed in load values and consequently stabilize the implant. The axial load in a single direction does not simulate the complex load system applied to the hip during walking, as well as the torsional forces and vectors orientation change during hip movements. However, all the shortcomings of this study probably give rise to quantitative differences (level of applied force) rather than qualitative. Therefore, they do not compromise the validity of the study. ${ }^{14,15}$
The choice of synthetic bone was determined to provide comparable biomechanical properties between the groups, eliminating variables. We, thus, withdraw possible changes inherent to human bones due to their non-uniform characteristics (bone density, diameter and length), that would make the evaluation method of fixation debatable, determining only the rigidity test of the implant.

The advantages of internal fixation (osteosynthesis) of femoral neck fracture with cannulated screws come from the technical ease of use and obedience to the principle of minimally invasive biological osteosynthesis, being these advantages perhaps insignificant to a good outcome of surgical treatment of the fracture femoral neck with unstable pattern, before the mechanical results from these tests.

We believe that the methodology for absolute stability and minimally invasive technique for femoral neck fracture is the best way to treat it, however, from the results obtained in this work we believe that there is a need to create new methods with better biomechanical results for this end.

\section{CONCLUSION}

There is a statistically significant difference between the control group, synthetic bone without synthesis, and the test group, synthetic bones with Pauwels type III fractures fixated with cannulated screws in ASNIS type parallel mount $(p=0.009)$. The fixation of Pauwels type III fracture with parallel cannulated screws (Asnis) in synthetic bones allowed on average $3.33^{\circ}$ rotational deviation.

\section{ACKNOWLEDGEMENTS}

We thank Prof. Ana Paula Patricia, Master's degree supervisor of Fundação de Ensino e Pesquisa em Ciência da Saúde (Fepecs), for her unconditional support.

\section{REFERENCES}

1. Javdan M, Bahadori M, Hosseini A. Evaluation the treatment outcomes of intracapsular femoral neck fractures with closed or open reduction and internal fixation by screw in 18-50-year-old patients in Isfahan from Nov 2010 to Nov 2011. Adv Biomed Res. 2013;2:14.

2. Woolf $A D$, Plefger B. Barden of major musculoskeletal condition. Bull World Health Organ. 2003; 81 (9): 646-56.

3. Henari S, Leonard M, Hamadto M, Cogley D. Review of a single contemporary femoral neck fracture fixation method in young patients. Orthopedics. 2011;34(3):171.

4. Asnis SE, Wanek-Sgaglione L. Intracapsular fractures of the femoral neck. Results of cannulated screw fixation. J Bone Joint Surg Am. 1994;76(12):1793-803.

5. Huang HK, Su YP, Chen CM, Chiu FY, Liu CL. Displaced femoral neck fractures in young adults treated with closed reduction and internal fixation. Orthopedics. 2010;33(12):873.

6. Kaplan T, Akesen B, Demirağ B, Bilgen S, Durak K. Comparative results of percutaneous cannulated screws, dynamic compression type plate and screw for the treatment of femoral neck fractures. Ulus Travma Acil Cerrahi Derg. 2012;18(1):65-70.

7. Huang HK, Su YP, Chen CM, Chiu FY, Liu CL. Displaced femoral neck fractures in young adults treated with closed reduction and internal fixation. Orthopedics. 2010;33(12):873.

8. Zlowodzki M, Brink O, Switzer J, Wingerter S, Woodall J Jr, Petrisor BA, et al. The effect of shortening and varus collapse of the femoral neck on function after fixation of intracapsular fracture of the hip: a multi-centre cohort study. J Bone Joint Surg Br. 2008;90(11):1487-94.

9. Denham RA. Hip mechanics. J Bone Joint Surg Br. 1959;41:550-557

10. Basile R, Pepiceli G, Takata E. Osteossintese da fratura do colo femoral: dois ou três parafusos?. Rev Bras Ortop. 2012;47 (2):165-8.

11. Walker E, Mukherjee DP, Ogden AL, Sadasivan KK, Albright JA. A biomechanical study of simulated femoral neck fracture fixation by cannulated screws: effects of placement angle and number of screws. Am J Orthop (Belle Mead NJ). 2007;36(12):680-4.

12. Lichtblau S, Gallina J, Nasser P, Munyoki M, Jepsen K. A biomechanical comparison of two patterns of screw insertion. Bull NYU Hosp Jt Dis. 2008;66(4):269-71.

13. Satish BR, Ranganadham AV, Ramalingam K, Tripathy SK. Four quadrant parallel peripheral screw fixation for displaced femoral neck fractures in elderly patients. Indian J Orthop. 2013;47(2):174-81.

14. Aminian A, Gao F, Fedoriw WW, Zhang LQ, Kalainov DM, Merk BR. Vertically oriented femoral neck fractures: mechanical analysis of four fixation techniques. J Orthop Trauma. 2007;21(8):544-8.

15. Sirkin M, Grossman MG, Renard RL, Sabatino CT, Doumas C, Reilly MC, et al. A biomechanical analysis of fixation constructs in high angle femoral neck fractures. Orthop Trauma Assoc. 1999. [Abstract 29]. 